\title{
LETRAMENTO DIGITAL: UMA REFLEXÃO SOBRE O MITO DOS “NATIVOS DIGITAIS"
}

\author{
Daniela Simone de Azevedo - PPGE da UFLA, profdaniaz@gmail.com \\ Aleph Campos da Silveira-PPGE da UFLA, alephcampos@gmail.com \\ Carla Oliveira Lopes - PPGE da UFLA, carla.oliveiralopes@ yahoo.com.br \\ Ludmila de Oliveira Amaral - PPGE da UFLA, ludmiladeoliveiraamaral@gmail.com \\ Ilsa do Carmo Vieira Goulart - DED/ PPGE da UFLA, ilsa.goulart@ded.ufla.br \\ Ronei Ximenes Martins - DED/ PPGE da UFLA, rxmartins@ded.ufla.br
}

\begin{abstract}
Resumo:
Neste tem-se por objetivo apresentar uma reflexão teórica de artigos que tematizam sobre letramento, letramento digital e digital literacy, direcionados a discutir sobre as habilidades que permeiam o desenvolvimento do letramento digital, enfatizando a questão do conceito "nativos digitais", refletindo sobre o papel do professor como mediador da aprendizagem neste contexto. Assume-se uma pesquisa com foco qualitativo, de cunho bibliográfico, tomando como procedimento metodológico a descrição a partir de uma reflexão teórica sobre as implicações das TDIC na leitura e escrita na Sociedade da Informação a partir dos trabalhos de Bennett, Maton e Kervin 2008; Bennett e Maton, 2010; Fajardo et. Al, 2016; Silva e Arturo, 2016; e confrontamos o conceito de Nativos Digitais criado por Marc Prensky (2001). A reflexão permitiu compreender que as habilidades que subjazem o letramento digital, incluem também a observação, a análise e a comparação de informações.

Palavras-chave: letramento digital, TDIC, multimodalidade, "nativos digitais".

\section{DIGITAL LITERACY: A REFLECTION ON THE MYTH OF THE DIGITAL NATIVES}

\section{Abstract:}

This text the objective of this article is to present a theoretical reflection of articles that focus on literacy, digital literacy and digital literacy, aimed at discussing the skills that permeate the development of digital literacy, emphasizing the question of the concept "digital natives", reflecting on the role of the teacher as mediator of learning in this context. It is assumed a research with qualitative focus, of bibliographic character, taking as a methodological procedure the description from a theoretical reflection on the implications of the TDIC in reading and writing in the Information Society from the works of Bennett, Maton and Kervin 2008; Bennett and Maton, 2010; Fajardo et. Al, 2016; Silva and Arturo, 2016; and we confront the concept of Digital Natives created by Marc Prensky (2001). The reflection allowed to understand that the abilities that underlie the digital literacy, also includes the observation, the analysis and the comparison of information.

Keywords: digital literacy, TDIC, multimodality, "digital natives".

\section{Considerações iniciais}

De acordo com Moran (1998), as Tecnologias Digitais de Informação e Comunicação (TDIC) são extensões de nosso corpo e mente, portanto, podem ser recursos que potencializam o humano. Considerando os avanços de Tecnologias de Informação e o acúmulo de informações, disponibilizadas e necessárias para formação de um estudante na contemporaneidade, as TDIC se tornam ferramentas indispensáveis para o processo de ensino e aprendizagem.

Partindo da premissa de que as Tecnologias Digitais de Informação e Comunicação (TDIC) alteraram as formas de relações socialmente construídas, rompendo limites de tempo de espaço, o que repercutiu, diretamente, nos modos de produção textual. O conceito de texto, antes entendido como uma escrita produzida de forma manuscrita e depois impressa, com o advento das tecnologias 
informacionais muda sua configuração, altera-se, ganhando outras dimensões e perspectivas, como textos multimodais e multissemióticos, que vão da escrita de palavras à composição de imagem em movimento. A diversidade de mídias e recursos informacionais alterou a forma de composição dos textos e dos meios em que são produzidos e compartilhados, conforme nos aponta Rojo (2009), tornam híbridos, visto que "[...] na vida contemporânea, em que os escritos e falas se misturam com imagens estáticas (fotos, ilustrações, gráficos, infográficos) e em movimento (vídeos) e com sons (sonoplastias, músicas), a palavra texto se estendeu a esses enunciados híbridos de "novo" tipo, de tal modo que hoje falamos também em textos orais e em textos multimodais, como as notícias televisivas e os vídeos de fãs no You Tube"1.

A escrita e a leitura com as TDIC vivem num estado de ressignificação constante. Tais atividades podem não ser estáticas, nem lineares, mas os textos escritos podem seguir o formato tradicional e transferir para as telas as mesmas formas da escrita e de leitura realizada nos suportes impressos, como por exemplo nos livros e cadernos. As relações entre os dispositivos de comunicação são reconfigurados e, com isso, as possibilidades e exigências de letramento também. (Ribeiro, 2012). Estas alterações, na forma de produção e de circulação dos textos, suscitam outras habilidades e modos de leitura e de interação entre o leitor e o texto. Requerem posturas e relações diferentes com a língua escrita e informações digitais. O letramento deixou de ser uma competência exclusiva da relação com os textos do mundo "real", para se relacionar com seu escritor/leitor num espaço paralelo, porém não menos real: o ciberespaço².

O ambiente digital instaurou na sociedade uma relação com textos e códigos, diferentemente daquelas já praticadas. Um ícone, um espaço, um clique, uma letra maiúscula, um emoticon, uma pontuação. Todas estas ações subjazem à leitura e à escrita no contexto digital. As TDIC estabeleceram que, além das habilidades de leitura e escrita, é preciso compreender-se como parte de uma cultura digital, participante de um mundo real, num contexto virtual. Transformaram-se os modos de ler e interpretar, escrever, colaborar e distribuir informações escritas ou orais e, haja vista que a instituição escolar é a principal agência de letramento da sociedade. Deste modo, considerar as implicações do conceito de letramento digital, no âmbito escolar, é pensar em como o uso das TDIC pode influenciar o processo de ensino e aprendizagem para o desenvolvimento da competência e fluência tecnológica, leitora e escritora.

Neste sentido, este artigo tem por objetivo apresentar uma reflexão teórica de artigos que tematizam sobre letramento, letramento digital e digital literacy, direcionados a discutir sobre as habilidades que permeiam o desenvolvimento do letramento digital, enfatizando a questão do conceito "nativos digitais", refletindo sobre o papel do professor como mediador da aprendizagem neste contexto.

Para tanto, optamos por realizar uma pesquisa com foco qualitativo, de cunho bibliográfico, tomando como procedimento metodológico uma reflexão teórica de artigos sobre a temática do letramento, letramento digital e digital literacy. A pesquisa foi realizada através do Portal de Periódicos Capes, a partir de uma busca por artigos publicados entre os anos de 2008 a 2018, com o uso dos descritores: "letramento" e "letramento digital", de modo que se retornou 58 artigos. A partir da leitura e das referências bibliográficas apresentadas nestes textos, foi necessário, entretanto, ampliar a pesquisa buscando outros artigos com os termos "letramentos", digital literacy, "múltiplos letramentos" e "textos multimodais"/ "multimodalidade", que são conceitos que dialogam com o tema do nosso artigo e que se complementam.

\footnotetext{
${ }^{1}$ Texto da autora publicado no Glossário do Ceale, online, sem número de página: http://www.ceale.fae.ufmg.br/app/webroot/glossarioceale/verbetes/textos-multimodais

${ }^{2}$ Como explicita Lévy (1999): “O termo [ciberespaço] especifica não apenas a infraestrutura material da comunicação digital, mas também o universo oceânico de informação que ela abriga, assim como os seres humanos que navegam e alimentam esse universo. Quanto ao neologismo 'cibercultura', especifica aqui o conjunto de técnicas (materiais e intelectuais), de práticas, de atitudes, de modos de pensamento e de valores que se desenvolvem juntamente com o crescimento do ciberespaço" (Lévy, 1999, p. 17).
} 
Percebemos que os termos: letramento, letramentos, multiletramentos e letramentos múltiplos são conceitos que se inter-relacionam. Assim, procuramos defini-los na busca de encontrar o ponto de interseção entre eles, como a competência que se refere à capacidade de ler, escrever, interpretar e compartilhar os diferentes gêneros textuais existentes, tanto nos suportes textuais impressos, quanto nos suportes digitais, que melhor evidenciam os textos multimodais ou multissemióticos.

Percebemos, também, que para tratar de letramento digital precisamos entender competência e fluência, literacy, ou melhor, letramento digital como a união de: (1) capacidades instrumentais de manipulação tecnológica, (2) integração da competência leitora/escritora na compreensão dos códigos, inter-relações das palavras e parágrafos, pontuação e significação dos vocábulos da língua Portuguesa e, (3) competência crítica de leitura e interpretação dos textos tradicionais e digitais. (Martin, 2008; Dias e Novais, 2009)

Tendo em vista tais considerações, neste texto refletimos sobre as implicações das TDIC na leitura e escrita na Sociedade da Informação a partir dos trabalhos de Bennett, Maton e Kervin 2008; Bennett e Maton, 2010; Fajardo et. Al, 2016; Silva e Arturo, 2016; e confrontamos o conceito de Nativos Digitais criado por Marc Prensky (2001) que aduz às habilidades naturais dos jovens nascidos a partir dos anos 90, na manipulação das tecnologias, pois consideramos que o uso das TDIC nas escolas pode ser um recurso capaz de desenvolver a leitura e escrita críticas, o que favorece a formação de cidadãos na sociedade chamada Sociedade da Informação, caracterizada pelo sociólogo Castells (2006) por uma sociedade conectada em uma dinâmica de redes, permeada pela internet e outras tecnologias.

\section{Sobre o letramento e o letramento digital}

Ao falarmos sobre as interseções existentes entre os diversos tipos de letramento, buscamos defini-los conjuntamente. Entretanto, algumas considerações são relevantes para compreender que aspectos nos levaram a conceber tal definição. Apesar dos "letramentos" se encontrarem em alguns aspectos, há características específicas que os distanciam em outros momentos. Tentaremos, portanto, refletir com o leitor, as aproximações e distanciamentos entre os termos para que o conceito amplo seja apreendido.

Letramento é um termo abrangente e por isso mais complexo. Ele está ligado a sociedade e a toda sua complexidade e não restrito ou relacionado apenas às atividades escolares, o que vem sendo muito debatido em função das inquietações sobre os usos da leitura e escrita, cada vez mais impostas pela sociedade multimodal e que vem sofrendo ressignificações em decorrência da inserção e ampliação do uso das TDIC em nossa sociedade. Frente a esta discussão, "[...] o conceito de letramento, que no início referia-se tão somente à leitura e à escrita convencional, foi estendido para outras esferas da construção do conhecimento, incluindo aí a esfera virtual, originando a expressão tão em voga atualmente: letramento digital". (Lima, 2008, p. 4).

O letramento envolve a aquisição das competências de leitura e escrita num processo de ampliação da alfabetização. Como diz Soares (2001, p.47) alfabetização é "[..] a ação de ensinar a ler e escrever" e letramento é "[...] o estado ou condição de quem não apenas sabe ler e escrever, mas cultiva e exerce práticas sociais que usam a escrita".

Bagno e Rangel (2005) definem letramento como um "conjunto de fatores socioculturais que, durante toda a existência de um indivíduo, lhe possibilitam adquirir, desenvolver e ampliar o conhecimento de/sobre sua língua materna, de/sobre outras línguas, sobre a linguagem de um modo mais geral e sobre todos os demais sistemas semióticos" (Bagno; Rangel, 2005, p. 63) ou, ainda, como afirma Britto: "o ensino da leitura, da redação, dos usos, do saber sobre a língua e dos valores que se constituem sobre ela". (Britto, 2003, p. 9). Diante de muitas definições, Ribeiro (2012, p. 38) aponta que "[...] não há um limite para o letramento, uma vez que a humanidade inventará formas novas de escrever, novos gêneros de textos, suportes de leituras, etc., de acordo com as infinitas necessidades que temos e teremos, fazendo com que o horizonte de letramento esteja em expansão". 
Se letramento tem um conceito tão amplo, o conceito de letramento digital não é muito diferente. O termo "letramento digital", de acordo com Lima (2008), surgiu na década de 1980, porém pode ser traçado originalmente desde a década de 40: inicialmente relacionado a um conceito técnico, ou seja, o estado ou a condição que adquire um grupo social ou um indivíduo como consequência de ter-se apropriado da escrita. A partir da década de 90, tornou-se fundamentalmente político por sua "inquestionável relação de poder econômico e social" graças ao advento tecnológico e popularização de tecnologias de informação. Ribeiro $(2012$, p. 40) aponta que "[...] num sistema de mídias composto por livros, televisões, computadores e seus aplicativos, tratar do letramento digital distingue um domínio do letramento".

Letramento digital, portanto, refere-se à capacidade de uso dos recursos informacionais e da internet para ler e escrever em situações diversas no ciberespaço, com uma ampliação do leque de possibilidades de contato com a leitura e escrita também no meio digital. $\mathrm{O}$ termo abarca não apenas conhecimentos do código alfabético e regras da língua escrita; ele amplia a interpretação de letramento, incluindo-se as capacidades de manipulação básica de hardwares e softwares e a compreensão dos contextos e finalidades dos textos digitais.

O leitor/escritor proficiente tornou-se aquele que possui competência básica de manipulação dos artefatos tecnológicos digitais, que já se apropriou da competência de leitura e escrita de textos impressos e aquele que consegue, a partir do uso das TDIC, movimentar-se e atuar no meio digital em que está inserido, como afirmam Leite e Botelho (2011, p. 3): “[...] não basta simplesmente saber ler e escrever é preciso fazer uso eficiente da leitura e da escrita em quase todas as práticas sociais".

\section{Competência digital para as novas formas de ler e escrever}

As habilidades tecnológicas básicas para o uso social da leitura e escrita na era digital, envolvem ações que permeiam a manipulação dos textos em tela e deveriam ser ensinadas e terem o uso estimulado desde a fase de alfabetização.

As telas e touchscreens ${ }^{3}$ como espaço de escrita e de leitura trouxeram novas necessidades para o uso da linguagem em "eventos de letramento" que "envolvem tipos específicos de percepção e de cognição do sujeito" e demandam a "superação de formas tradicionais de aprendizagem pela recuperação, reinserção e dinamização das dimensões interativa e lúdica do processo". (Silva et al. 2003, p. 50)

Aprender as letras, as sílabas, as relações entre as palavras e a manipulação dos textos e folhas dos livros e cadernos são habilidades que iniciam e inserem os cidadãos nas práticas letradas, juntamente com a capacidade de análise crítica das mensagens e ideologias que permeiam os textos. Por outro lado, usar o mouse para localizar-se na tela, conhecer as funções dos cliques, enters, deletes e backspaces são ações que formam, paralelamente, a competência tecnológica capaz de possibilitar esta inserção do sujeito nas práticas letradas em contexto digital, chamada de literacy, letramento digital ou competência digital. A discussão em outros países retrata que a "[...] chegada dos computadores e da comunicação multimídia fez com que fossem necessárias mais aptidões e competências avançadas, sendo assim necessário falar em literacia digital". (Tornero; Varis, 2010, p. $32)^{4}$

A competência digital, no entanto, não implica apenas em ações instrumentais de uso dos artefatos tecnológicos. Para ser um letrado digital é também necessário desenvolver capacidades que permitam compreender e dominar a linguagem codificada e subjacente à cibercultura (Levy, 1999). Segundo o Quadro de Referência Europeu sobre Competências-chave para a Aprendizagem ao Longo da Vida (Comissão Europeia, 2007a) a competência digital envolve "[...] a utilização segura e crítica das tecnologias da sociedade da informação (...) [é] sustentada pelas competências em TIC: o uso do

\footnotetext{
${ }^{3}$ Tela sensível ao toque.

${ }^{4}$ Original em inglês: "with the arrivel of computers and multimedia communication, more advanced capacities and competences were needed. We then speak about digital literacy".
} 
computador para obter, avaliar, armazenar, produzir, apresentar e trocar informações e para comunicar e participar em redes de cooperação via Internet". (Comissão Europeia, 2007a, p. 7).

É notório como as tecnologias ocuparam papel de destaque no dia a dia da sociedade, seja para a comunicação, estudo, deslocamento, compras, registros de memórias e até para mediação dos relacionamentos interpessoais. Neste sentido, a competência digital deixa de ser considerada como uma habilidade apenas de utilização instrumental da tecnologia e passa a refletir as práticas sociais. (Freitas, 2010). Assim, surgem novas demandas de aprendizado para o convívio em uma sociedade conectada e o aprendizado tradicional de leitura e escrita não é mais suficiente para o desempenho de atividades simples no trabalho, escolas e na vida social.

É neste novo contexto social que surge o letramento digital. De acordo com Santos et. al (2016), literacia (competência) digital é o conceito que integra outras literacias, como: computer literacy, information literacy, network literacy, digital literacy e media literacy:

Fará sentido que a literacia digital seja vista como o conceito integrador de literacias prévias ao grande crescimento do contexto digital, daquelas, cujo enfoque é o conhecimento técnico e uso de aplicações bem como de outras competências que destacam sobretudo a tendência para o uso de media sociais e participativos e da sua importância para novas formas de comunicação, expressão, viver, aprender e trabalhar. (Santos et al, 2016, p. 03)

Educações mediadas por tecnologias ainda estão sendo exploradas e revelam um campo carente de desenvolvimento em diversas áreas. Do ponto de vista do aluno, é notado que, diferente da tese de Prensky (2001), ele muitas vezes não é nativamente adaptado ao uso de novas tecnologias e/ou formas ensino-aprendizagem que mesclem o uso de tecnologias com objetivos específicos e intencionais, conforme nos apontam Bennett, Maton y Kervin (2008); Bennett y Maton (2010), Fajardo et. al (2016), ECDL Fundation (2016), entre outros.

Embora a referência desta discussão seja de uma geração que nasce conectada, entendemos que a sociedade informatizada, ainda precisa ser alfabetizada e ser desenvolvido conhecimentos de base conceitual e procedimental, mediados por professores de outras gerações. Por isso, o professor, apto ao uso de novas tecnologias, garante proximidade com a grupo conectado, favorecendo novas relações com o conhecimento na implementação e administração de TDIC em salas de aula. Longe da concepção da perda da importância ou da necessidade do docente em salas de aula, o professor é reconhecido como agente mediador e instigador da aprendizagem utilizando ferramentas tecnológicas. A presença de ferramentas e softwares como smartphones e whatsapp, já se encontram presentes em sala de aula, porém não ainda utilizados com devido potencial. O professor atua como agente mediatário, pois a educação é feita de uma relação essencialmente humana. Mesmo que mediado pela tecnologia, o processo de aprendizagem mantém raízes na interrelação entre diferentes indivíduos. O professor tem o papel de orientar e direcionar os educandos. Por desenvolver em conjunto aos estudantes "[...] um senso de autonomia perante quando e como usar recursos digitais de comunicação dentro da escola é parte integrante da preparação para a vida, ainda mais porque esse jovem sai da escola e têm, em ambientes de trabalho e de vida social, que exercer esse mesmo uso automonitorado". (Pereira e Maciel, 2017, p. 74).

A aquisição do letramento digital é colocada como um compromisso educacional e de sobrevivência. (Xavier, 2005). O professor tem o desafio de letrar digitalmente os educandos, para a sociedade da informação e do conhecimento.

\section{O mito do nativo digital}

O termo "nativo digital", é usado para designar a geração que nasceu a partir de 1980 e que foi criada com a presença ubíqua dos artefatos tecnológicos, que segundo as descrições de Prenski (2001, p.1): 
O termo "nativo digital" foi cunhado em 2001 pelo autor americano Marc Prensky. Em seu artigo "Nativos digitais, imigrantes digitais", Prensky define "nativos digitais" como jovens que cresceram cercados e usando computadores, telefones celulares e outras ferramentas da era digital. $\mathrm{O}$ autor afirmou que um ambiente digital muda drasticamente a maneira como os jovens pensam e processam informações, e até mesmo isso modifica suas estruturas cerebrais. ${ }^{5}$ (ECDL Fundation, 2016, p. 01)

Se considerarmos as afirmações de Prenski (2016, p.2), as pessoas nascidas na geração "Nativos Digitais" seriam proficientes, fluentes ou com domínio inato das tecnologias digitais e quem nasceu anteriormente seria chamada por ele de imigrantes digitais, destinados a ficar sempre "com um pé no passado". No entendimento do autor, o fato de terem nascido na era das tecnologias digitais faria daquela geração, uma geração diferente da anterior, com características que os fariam pensar e processar as informações de maneira diversa de qualquer imigrante digital.

As leituras que fizemos de Bennett, Maton e Kervin (2008); Bennett e Maton (2010), Fajardo et. Al (2016), Silva e Arturo (2016), entretanto, levaram-nos a refutar as afirmações de Prenski sobre os "nativos digitais", que concluímos, ter sido parcial, precipitada e não comprovada por métodos científicos. Afirmações sobre uma geração que estaria exposta a novas tecnologias e possibilidades e, que, "poderia" vir a utilizá-las de forma a transformar sua maneira de relacionar-se com as informações e com o conhecimento. Para os autores Silva e Arturo (2016), titular esta geração como apta, naturalmente, ao uso das tecnologias foi um erro.

A potência dessa categoria é indubitável: ela encapsulou três fenômenos que estavam afetando cada vez mais o imaginário coletivo do Ocidente, gerando um ardor e, em muitos, abertamente o medo. Em primeiro lugar, a extrema velocidade com a qual o digital filtrou nossa vida diária; segundo, a facilidade com que aparentemente os jovens lidaram com isso, bem como o papel preponderante disso em suas vidas; e, terceiro, o inegável impacto do primeiro nos processos educacionais. No entanto, a fragmentação da sociedade em nativos e imigrantes serviu para apontar outro capítulo no proverbial pânico social contra a tecnologia, que então seria, como seria de esperar, estimulado, hiperbolizado e dramatizado pela mídia e por certos autores insidiosos. (Silva; Arturo, 2016, p. 472)

Pertencer ou não a categoria dos "nativos digitais" não define as capacidades de usar as TDIC de forma consciente e para realizar tarefas de estudo ou trabalho. Para ser capaz de atuar no mundo atual, em que as informações são extremamente rápidas e as relações "líquidas" (Bauman, 2001). É preciso mais do que ter nascido e crescido em contato com os artefatos tecnológicos. O uso consciente das tecnologias deve ser ensinado e aprendido, como qualquer outra habilidade cognitiva.

Sobre isso, Fajardo et. al. (2016) ao comentar os estudos de Prensky (2001) da existência da crença generalizada de que os estudantes de hoje pertencem a uma geração de "nativos digitais", afirmam que:

[...] pelo que se tem a assumir é que estes alunos já possuem as habilidades digitais básicas para manejar as tarefas de leitura digital como programadas por PISA. Nossos resultados chocam, frontalmente, com esta visão de aluno e enfatizam a necessidade de abordar diretamente a instrução destas habilidades para evitar uma maior brecha digital entre os estudantes com altas e baixas habilidades. Como

\footnotetext{
${ }^{5}$ Cf. texto original: "El término "nativo digital" fue acuñado en 2001 por el autor estadounidense Marc Prensky. En su artículo "Nativos digitales, inmigrantes digitales" Prensky define a los "nativos digitales" como jóvenes que crecieron rodeados y utilizando computadoras, teléfonos celulares y otras herramientas de la era digital. El autor afirmó que un entorno digital cambia drásticamente la forma en que los jóvenes piensan y procesan la información, e incluso, que posiblemente cambia sus estructuras cerebrales". (ECDL Fundation, 2016, p. 01)
} 
sugerem Brand-Gruwel y cols. (2009), as habilidades digitais básicas são um prérequisito para poder adquirir as competências de leitura digital. ${ }^{6}$

Ensinar a ler e escrever no contexto atual pressupõe que professores refutem a ideia que os "nativos digitais" já sabem utilizar as tecnologias para se incluírem nas práticas sociais, é importante que o professor compreenda a significância de proporcionar momentos de uso das TDIC para a prática de leitura e escrita em ambientes digitais, pois só assim o estudante estará diante de situações reais de uso, buscará desenvolver as habilidades necessárias para se deslocar e atuar para e com a cultura digital. Dessa forma, é importante que os professores se preocupem em ensinar as habilidades técnicas, que são necessárias para manusear os diferentes recursos tecnológicos, bem como ensinarem o metaconhecimento, para que haja uma compreensão das diferentes mídias e seu funcionamento de forma significativa. Os educadores precisam possibilitar situações de ensino para se desenvolver o conhecimento e as habilidades necessárias para se construir significados. A multimodalidade pode contribuir para o entendimento dos contextos de comunicação, focando em modos e mídias específicos, em determinados contextos sociais e culturais.

\section{Habilidades para o letramento digital}

Compreendendo, portanto, que os jovens precisam desenvolver-se também, tecnologicamente, para a inclusão social a partir das novas relações digitais, Dias e Novais (2009, p.7) construíram uma matriz de referência para o letramento digital e apontaram quatro grandes "ações de usuários competentes", como sendo "as principais habilidades que um usuário deve construir para desenvolver os seus diversos letramentos digitais, independente da natureza de suas práticas": (1) Utilizar diferentes Interfaces; (2) Buscar e organizar informações em ambiente digital; (3) Ler hipertexto digital e (4) Produzir textos (orais ou escritos) para ambientes digitais.

Cada uma destas grandes ações compreende "descritores", que podem ser considerados ações subjacentes, detalhados pelos autores, em planilhas específicas da matriz de referência. Para ampliar o entendimento do uso das tecnologias no desenvolvimento do letramento digital, selecionamos alguns destes "descritores", adaptando-os e reorganizando-os, mediante o uso recorrente e essencial, percebido na realização de projetos e atividades ${ }^{7}$, nos anos finais do Ensino Fundamental e EJA, voltados à aquisição e apropriação do letramento digital com mediação das TDIC. Além disso, para um melhor entendimento das relações entre o aprendente e as TDIC dividimo-los em classes de ações, semelhantes às grandes ações citadas por Dias e Novais (2009, p. 7), sendo elas: Instrumentais, Interativas, Interacionais e Críticas.

As ações denominadas "Instrumentais" se referem ao uso dos instrumentos tecnológicos. Saber usar o mouse, teclado, ligar e desligar o computador, melhorar a imagem através dos controles de brilho, contraste, nitidez, reconhecer as partes do computador e os meios de gravação e arquivo dos dados.

As consideradas "Interativas" são ações relativas à relação entre o usuário e o ambiente digital, refere-se instrumentos ou recursos que oferecem a própria mediação ao usuário, como conhecer os softwares e aplicativos que mediam a leitura e a escrita digital e saber manipulá-los. Dominar as competências de leitura "em tela": uso das barras para movimentar-se na página, recursos de zoom e leitura em tela cheia, localização de softwares e aplicativos, etc. Conhecer os tipos de

\footnotetext{
${ }^{6}[\ldots]$ por lo que se tiende a asumir que estos alumnos ya poseen las habilidades digitales básicas para manejarse en las tareas de lectura digital como las planteadas por PISA. Nuestros resultados chocan frontalmente con esta visión del alumnado, y enfatizan la necesidad de abordar directamente la instrucción de estas habilidades para evitar una mayor brecha digital entre los estudiantes con altas y bajas habilidades. Como sugieren Brand-Gruwel y cols. (2009), las habilidades digitales básicas son un prerrequisito para poder adquirir las competencias de lectura digital". (2016, p. 96-97)

${ }^{7}$ Alguns dos projetos desenvolvidos no ensino fundamental e EJA: Uso da Internet na Educação (2001); Desenvolvimento de vídeo para a aula de Inglês (2015); Construindo um blog a partir de atividades realizadas em sala de aula (2012); Lendo e interpretando comandos a partir da tela do computador (2015); Aulas de Informática na escola (2016); Ensinando Linux na Eja (2016).
} 
textos digitais e suas funções e saber acessá-los. Conhecer as regras de interação e escrita em chats, fóruns, $e$-mails e outros ambientes digitais de produção escrita.

As caracterizadas como "Interacionais" remetem às ações relativas às relações do usuário, no contexto digital, com outros usuários e com o próprio ambiente ${ }^{8}$, ao compreender os espaços de escrita virtual como espaços públicos; ao compreender as regras dos direitos autorais, utilizando-as na reprodução e distribuição de textos digitais; ao conhecer as regras de comunicação online, no contexto em que estiver produzindo textos; ao escolher vocabulário e códigos adequados e pertinentes ao ambiente virtual; ao ser capaz de selecionar e organizar as informações que busca e produz em ambiente virtual.

As ações "Críticas" são relativas à compreensão da cultura digital e suas ideologias. Envolvem ações de reconhecer a dimensão social em que os textos digitais são produzidos e lidos; entender o que são e quais os desdobramentos dos hipertextos, de forma a delinear seu próprio caminho de leitura; comparar e selecionar informações relevantes e verdadeiras no vasto espaço digital.

É possível perceber, a partir dos grupos de ações descritos, que a competência de ler e escrever em ambiente digital, portanto, não perpassa apenas pelas tecnologias. Ser letrado digital é assumir mudanças no modo de ler e escrever. Entretanto, muitas são as habilidades tecnológicas que compõem esta competência. Por outro lado estes descritores nos mostram que não se pode tratar do uso das TDIC como mero modismo ou formalidade curricular, eles nos levam à compreensão de que um indivíduo letrado digitalmente não é aquele que apenas utiliza as tecnologias como instrumentos de acesso, ao contrário, aquele que compreende-se inserido num contexto maior, em que os recursos digitais compõem uma sociedade híbrida, que relaciona-se através das práticas digitais e que interage ora pessoalmente, num mundo denominado "real", ora num mundo cibernético porém não menos real. "Em um certo sentido, o Letramento digital luta contra a ideia de ensino/aprendizagem como preenchimento das 'mentes vazias' do aluno". (Xavier, 2007, p. 2).

O entendimento de letramento digital, diante da observação dos descritores digitais elencados anteriormente, é algo que muda profundamente a relação de ensino com as TDIC, porque nos leva à visão dos seus diversos componentes, inter-relacionados e complementares.

\section{Considerações finais}

Ao discutimos, ao longo deste artigo, sobre conceitos como letramento digital e "nativos digitais", sedimentam à compreensão de que é emergente a promoção da prática e uso das TDIC no ensino, mas não como instrumentos de acesso ao mundo virtual. O uso de um instrumento tecnológico de maneira repetitiva e automática não é suficiente para que o seu usuário seja um sujeito capaz de analisar as implicações sociais da cultura digital. Nossa reflexão permitiu compreender que as habilidades que subjazem o letramento digital, incluem também a observação, a análise e a comparação de informações. A aprendizagem com o uso das TDIC propicia o desenvolvimento de indivíduos críticos e autônomos, capazes de atuar na e com a sociedade, no momento de sua aprendizagem e no futuro, quando de sua inserção no mercado de trabalho.

$\mathrm{Na}$ dimensão crítica, da reflexão teórica realizada, percebemos a necessidade de que outros trabalhos sejam desenvolvidos a fim de esclarecer as características de uma geração que nasce em um mundo da informação e deve aprender a lidar com a tecnologia de forma produtiva. É importante ainda que sejam desvendados os mitos em torno dos chamados "nativos digitais" e que possamos

\footnotetext{
${ }^{8}$ Remetendo ao termo apresentado por Castanheira no Glossário Ceale: "Evento interacional é um conceito analítico usado no exame do modo de construção da vida de um grupo social por meio da interação, verbal e não verbal, entre seus participantes, ao longo do tempo. Reconhecimento de que a vida social é produzida por meio da contínua interação entre participantes em situações comunicativas sustenta o interesse em se examinar como tais situações são construídas, momento a momento, pelos seus participantes e pela análise das consequências que tais construções têm para a vida de indivíduos e/ou grupos sociais a que pertencem". Disponível online e sem número de páginas em: http://ceale.fae.ufmg.br/app/webroot/glossarioceale/verbetes/evento-interacional
} 
preparar os educadores para que exerçam com excelência as propostas educativas em mundo diferente do que foram, inicialmente, formados, um mundo mais complexo e com novos desafios.

\section{Referências}

BAGNO, M.; RANGEL, E. O. Tarefas da educação linguística no Brasil. Revista Brasileira de Linguística Aplicada, Belo Horizonte, v. 5, n. 1, 2005.

Disponível em: http://www.scielo.br/scielo.php?script=sci_arttext\&pid=S1984$\underline{63982005000100004 \& \operatorname{lng}=e n \& n r m=i s o}$. Acesso em: 19 jun. 2018.

BRITTO, L. P. L. Educação e Política: Sobre o Conceito de Letramento. In: BRITO, L. P. L. Contra o consenso: cultura escrita, educação e participação. Campinas: Mercado das Letras, 2003.

BERGMANN, J.; SAMS, A. Flipped Learning: Gateway to Student Engagement. Capa comum: 169 páginas Editora: International Society for Technology in Education. 2014.

CASTANHEIRA, M. L. Evento interacional. Disponível em: http://ceale.fae.ufmg.br/app/webroot/glossarioceale/verbetes/evento-interacional. Acesso em: $12 \mathrm{jul}$. 2018.

CASTELLS, M.; FERNANDEZ-ARDEVOL, M.; LINCHUAN QIU, J.; SEY, A. Mobile Communication and Society: A Global Perspective. MIT Press: Cambridge, Massachusetts. 2006.

CHRISTENSEN, Clayton M.; EYRING, Henry J. A universidade inovadora: mudando o DNA do ensino superior de fora para dentro. Porto Alegre: Bookman, 2014.

COMISSÃO EUROPEIA. Competências-chave para a Aprendizagem ao Longo da Vida. Quadro de Referência Europeu. 2007a. Disponível em: http://goo.gl/eVJiyo Acesso em: 23 jun. 2018.

DIAS, Marcelo Cafiero; NOVAIS, Ana Elisa. Por uma Matriz de Letramento Digital. In: ENCONTRO NACIONAL SOBRE HIPERTEXTO, 3., 2009, Belo Horizonte. Centro Federal de Educação Tecnológica de Minas Gerais, Belo Horizonte, 2009.

FREITAS, M. S. Letramento digital e formação de professores. Educação em Revista, Belo Horizonte, vol. 26, n. 3, p.335-352, 2010. Disponível em: http://www.scielo.br/pdf/edur/v26n3/v26n3a17 Acesso em: 24 de jun. 2018.

FAJARDO, Inmaculada; VILLALTA, Ester; SALMERÓN, Ladislao ¿Son realmente tan buenos los nativos digitales? Relación entre las habilidades digitales y la lectura digital. Anales de Psicología [em linea] 2016, 32 (Enero-Sin mes). Disponível em: http://www.redalyc.org/articulo.oa?id=16743391010

Acesso em: 28 jun. 2018.

KIRKWOOD, A.; PRICE, L. Learners and learning in the twenty-first century: what do we know about students' attitudes towards and experiences of information and communication technologies that will help us design courses? Studies in Higher Education, vol. 30, n. 3, p. 257-274, 2005. Disponível em: https://www.unil.ch/files/live/sites/magellan/files/shared/Are_digital_natives_a_myth_or_reality_p df Acesso em: 21 jun. 2018. 
KOH, J. H. L; CHAI, C. S. Seven design frames that teachers use when considering technological pedagogical content knowledge (TPACK). Computers \& Education, vol.102, p.244-257, November 2016.

LÉVY, P. Cibercultura. Tradução de Carlos Irineu da Costa. São Paulo: Ed. 34, 1999.

LIMA, M. C. A. Experienciando o letramento digital: sistematização de uma pesquisa-ação online. Revista do GEL, São Paulo, v. 5, n. 2, p. 213-224, 2008.

MARGARYAN, A.; LITTLEJOHN, A.; VOJT, G. Are digital natives a myth or reality? University students'use of digital technologies. Computers \& Education, vol. 56, fev. 2011, p. 429-440. Disponível em: https://www.sciencedirect.com/science/article/pii/S0360131510002563. Acesso: 20 jun. 2018.

MORAN, J. M. A educação que desejamos: novos desafios e como chegar lá. Campinas: Papirus, 2007.

MORAN, J. M. Mudanças na comunicação pessoal: gerenciamento integrado da comunicação pessoal, social e tecnológica. São Paulo: Paulinas, 1998.

PEREIRA, V. C.; MACIEL, C. Twitteratura: aproximando letramento literário e letramento digital. Revista do Programa de Estudos Pós-Graduados em Literatura e Crítica Literária da PUC-SP. n. 18, jul. 2017. Disponivel: http://dx.doi.org/10.23925/1983-4373.2017i18p60-77 Acesso: 20 jun. 2018.

PRENSKY, M. Digital Natives, Digital Immigrants. On the horizont, v. 9, n. 5, out. 2001. RIBEIRO. A. E. Novas tecnologias para ler e escrever: algumas ideias sobre ambientes e ferramentas digitais na sala de aula. Belo Horizonte: RHJ, 2012.

ROJO, Roxane. Letramentos múltiplos, escola e inclusão social. São Paulo: Parábola Editorial, 2009.

SANTOS, Rita; AZEVEDO, José; PEDRO, Luís. Literacia(s) digital(ais): definições, perspectivas e desafios. Media \& Jornalismo, [S.1.], v. 15, n. 27, p. 17-44, set. 2016. Disponível em: http://impactum-journals.uc.pt/mj/article/view/3485. Acesso em: 24 jun. 2018.

SILVA, H. et al. A Inclusão digital e educação para a competência informacional: uma questão de ética e cidadania. Ciência da Informação, Brasília, v. 34, p. 28-36, jan./ abr. 2005. Disponível em: http://www.scielo.br/scielo.php?script=sci_arttext\&pid=S0100-

19652005000100004\&lng=en\&nrm=iso. Acesso em: 18, jun. 2018.

SILVEIRA, A. C.; ALVARENGA, R. C.; MARTINS, R. X. Desenvolvimento de um aplicativo para auxílio do ensino da tabela periódica. Congresso Brasileiro de Ensino Superior a Distância, ESUD, 14., 2017, Rio Grande. Editora da FURG, v. 11. p. 81-91, 2017.

SINGER, Paul. Aprender economia. São Paulo: Brasiliense, 1983.

SOARES, Magda. Letramento: um tema em três gêneros. 2. ed. Belo Horizonte: Autêntica, 2001. 
- Novas práticas de leitura e escrita: letramento na cibercultura. Revista Educação e Sociedade, Campinas: Cedes, vol. 23, n. 81, 2002.

TORNERO, J. M. P.; VARIS, T. Media Literacy and New Humanism. UNESCO. Disponível em: http://unesdoc.unesco.org/images/0019/001921/192134e.pdf Acesso em: 22, jun. 2018.

XAVIER, A. C. S. Letramento digital e ensino. 2007. Disponível em: https://escolafutura.files.wordpress.com/2013/11/letramento-digital-e-ensino.pdf. Acesso em: 19 jun. 2018. 